\title{
Effects of extracts from two Native American plants on proliferation of human breast and colon cancer cell lines in vitro
}

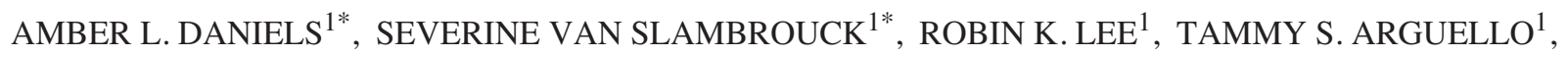 \\ JAMES BROWNING $^{1}$, MICHAEL J. PULLIN ${ }^{2}$, ALEXANDER KORNIENKO ${ }^{3}$ and WIM F.A. STEELANT ${ }^{1}$ \\ ${ }^{1}$ Laboratory of Biochemical and Biomedical Research, ${ }^{2}$ Laboratory of Aqueous Environmental Chemistry, ${ }^{3}$ Laboratory of \\ Synthetic Organic and Medicinal Chemistry, Department of Chemistry, New Mexico Tech, Socorro, NM, USA
}

Received December 8, 2005; Accepted January 24, 2006

\begin{abstract}
Native American medicinal plants are traditionally used to prevent and treat a variety of diseases, including cancer. These herbal preparations are alleged to have many biological activities, such as stimulation or suppression of immune responses and antiproliferative effects on cancer cells. In the present study, we investigated the effects of aqueous and ethanol extracts from two Native American plants, Ligusticum porteri (Osha) and Anemopsis californica (Yerba Manza), on the growth of human MCF-7/AZ breast and HCT8/E11 colon cancer cells. The aqueous and ethanol extracts from A. californica potently inhibited growth of $\mathrm{MCF}-7 / \mathrm{AZ}$ in a concentration-dependent manner, whereas the growth of HCT8/E11 was unaltered. Extracts from $L$. porteri showed no activity on either cell line. In addition, we observed that the extracellular signal-regulated protein kinase 1 and 2 (ERK1/2) activities were markedly decreased when exposed to both extracts from A. californica. These results suggest that the growth inhibitory effect of $A$. californica in breast cancer cells is ERK-mediated.
\end{abstract}

\section{Introduction}

Cancer is one of the major causes of death in the U.S. and accounts for $22 \%$ of all annual deaths (1). Common methods of treatment have yielded some benefits (2), but there is a significant need to improve current cancer therapies and

Correspondence to: Professor Wim F.A. Steelant, Department of Chemistry, Laboratory of Biochemical and Biomedical Research, New Mexico Tech, 801 Leroy Place, Socorro, NM 87801, USA

E-mail: steelant@nmt.edu

${ }^{*}$ Contributed equally

Abbreviations: ERK1/2, extracellular signal-regulated kinases; OD, optical density

Key words: Ligusticum porteri (Osha), Anemopsis californica (Yerba Manza), Native American medicinal plants, breast cancer, growth, extracellular signal-regulated protein kinases search for novel therapies. Throughout medical history, plant-derived products have been shown to be valuable sources for the discovery and development of unique anticancer drugs (3). Several therapies used today trace their origin to plants: Vinca alkaloids (vincristine and vinblastine) isolated from Catharanthus roseus (4), taxanes (paclitaxel and docetaxel) derived from the Pacific yew Taxus brevifolia (5), and camptothecins from the Chinese tree Camptotheca acuminata (6).

In the present study, we determined the activity of extracts from two medicinal plants, Ligusticum porteri (Osha) and Anemopsis californica (Yerba Manza), used by Native American tribes in New Mexico, on human tumor cell lines. These plants are traditionally used to treat a variety of diseases, including cancer, according to centuries-old knowhow. Scientific knowledge concerning biological activity and active components in $L$. porteri and A. californica is rather limited (7).

Aqueous and ethanol extracts were prepared from L.porteri and A. californica, and subsequent cytotoxic concentration of the obtained extracts was determined on MCF/7-AZ breast and HCT8/E11 colon cancer cells. Furthermore, the effect of these extracts on cancer cell growth was analyzed in vitro. In addition, studies were conducted to detect changes in the activity level of extracellular signal-regulated protein kinases 1 and $2($ ERK1/2) when cells were exposed to extracts and compared to unexposed cells. The ERK signaling pathway has been linked to cell proliferation and cell survival and represents an attractive target for anticancer therapy (8). Several natural products are reported to alter ERK activities (9).

In this study we demonstrate that aqueous and ethanol extracts of A. californica inhibit growth of breast cancer cells in a concentration-dependent manner. We also observed that ERK activities were noticeably decreased, suggesting that the ERK signaling pathway could be an intracellullar target for biological activity by A. californica in breast cancer cells.

\section{Materials and methods}

Plant extracts. Ligusticum porteri (Osha) and Anemopsis californica (Yerba Manza) were collected in New Mexico, USA. The dried plants ( $75 \mathrm{~g}$ ) were soaked in water or ethanol for $24 \mathrm{~h}$, then the mixtures were filtered to remove particulate 
Extract

MCF-7IAZ

A. californica Aqueous

A. californica Ethanol
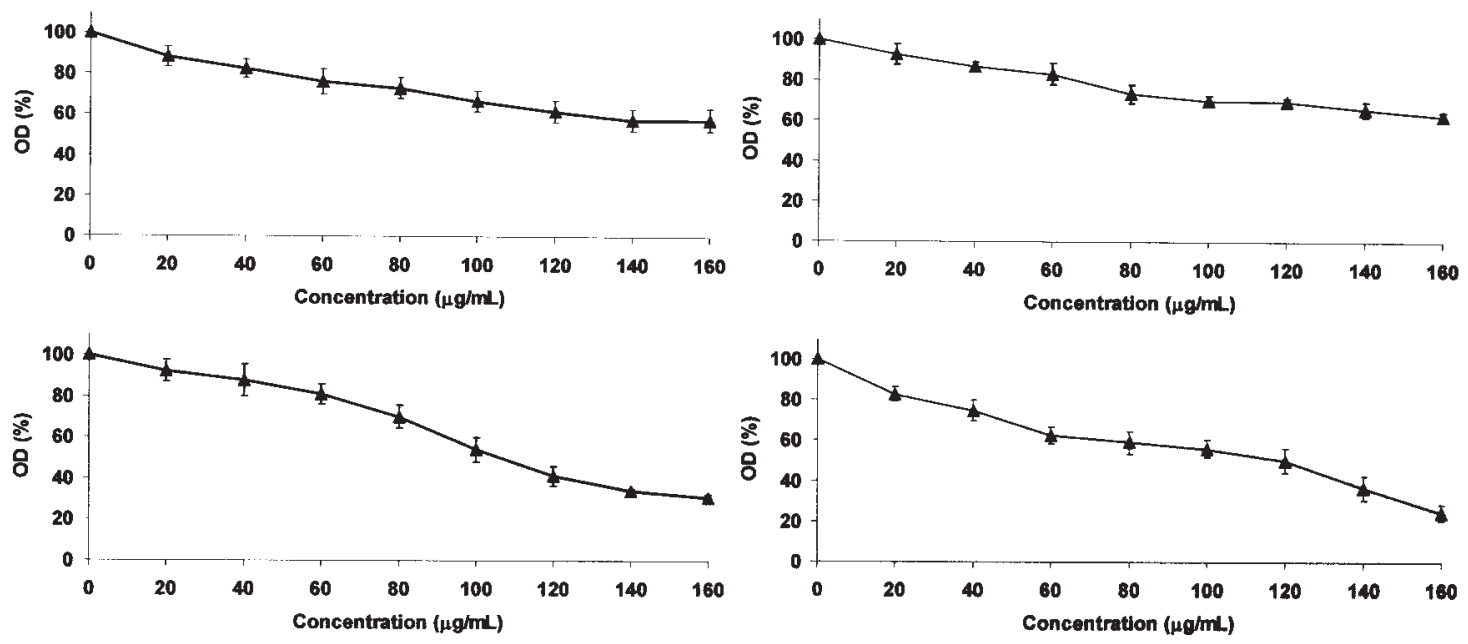

Figure 1. Cells exposed to various concentrations of aqueous and ethanol extracts from A. californica for $24 \mathrm{~h}$. The percentage of cell viability was determined by MTT assay. Each data point represents the mean and standard deviations of results from three individual measurements.

matter and lyophilized. The obtained yields were $9.8 \%$, $10.0 \%, 11.0 \%$ and $12.5 \%$, respectively, and the resulting powders were stored in a desiccator at $4^{\circ} \mathrm{C}$.

Cell culture. MCF-7/AZ is a variant of the human mammary carcinoma cell family MCF-7 (10). The cells are maintained on tissue culture plastic substrate (Nunc) in a mixture of Dulbecco's modified Eagle's medium (DMEM) and HAMF12 (50/50) (Invitrogen, CA) supplemented with $250 \mathrm{IU} / \mathrm{ml}$ penicillin, $100 \mu \mathrm{g} / \mathrm{ml}$ streptomycin (Invitrogen) and 10\% fetal bovine serum (FBS) (Invitrogen). The human colon cancer cell line HCT-8/E11 (11) was cultured in DMEM supplemented with $10 \% \mathrm{FBS}, 100 \mathrm{U} / \mathrm{ml}$ penicillin and $100 \mu \mathrm{g} / \mathrm{ml}$ streptomycin.

Assay for cell viability. Cell viability was tested in accordance with Romijn et al (12). Briefly, mitochondrial dehydrogenase activities were measured by an MTT reagent (Sigma, St. Louis, MO, USA). Cells were seeded in microtiter plates at an initial density of $1.5 \times 10^{4}$ cells in $200 \mu 1$ culture medium. The mean optical density (OD) was reported as a function of increasing powder extract concentration. In each experiment, eight wells were used to determine the mean OD. The experiment was repeated at least three times for each extract per cell line.

Assay for cell growth. Cells were seeded in microtiter plates at an initial density of $1.5 \times 10^{4}$ cells in $200 \mu 1$ culture medium or in $25 \mathrm{~cm}^{2}$ culture flasks at a density of $1.0 \times 10^{5}$ cells in $5 \mathrm{ml}$. After an incubation period of 4 days, the amount of cell protein in each well was estimated with the sulforhodamine B assay (13) or cells were counted with a hemacytometer (Hausser Scientific, PA, USA).

Western blot analysis. Cell lysates were made from $70 \%$ confluent cultures. Cells were treated for indicated times with aqueous and ethanol extracts of $L$. porteri and A. californica. After incubation, cells were washed three times with PBS. Cells were lysed in $0.5 \mathrm{ml}$ lysis buffer containing $1 \%$ Triton

\section{Extract}

MCF-7IAZ
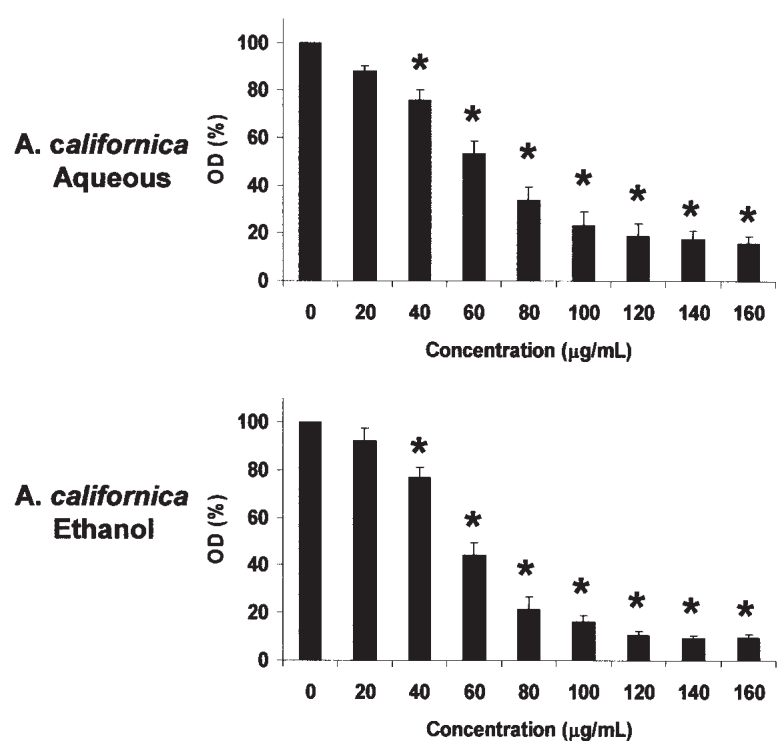

Figure 2. Effects of aqueous and ethanol extracts from A. californica on growth of MCF-7/AZ cells. The cells were exposed to various concentrations for 4 days, and the amount of cellular protein was measured with the sulforhodamine B assay and expressed as optical density (OD). Bars and flags indicate mean values and standard deviations. ${ }^{*}$ Indicates statistical difference from control.

$\mathrm{X}-100,1 \% \mathrm{NP}-40$ and the following protease inhibitors: aprotinin $(10 \mu \mathrm{g} / \mathrm{ml})$, leupeptin $(10 \mu \mathrm{g} / \mathrm{ml}), \operatorname{PMSF}(1.72 \mathrm{mM})$, $\mathrm{NaF}(100 \mathrm{mM}), \mathrm{NaVO}_{3}(500 \mu \mathrm{M})$ and $\mathrm{Na}_{4} \mathrm{P}_{2} \mathrm{O}_{7}(500 \mu \mathrm{g} / \mathrm{ml})$. Protein concentration was determined using the Pierce BCA protein assay kit (Pierce, IL, USA). Aliquots of lysates containing the same quantity of proteins were boiled for $5 \mathrm{~min}$ in SDS-PAGE sample buffer containing 5\% B-mercaptoethanol, electrophoresed on 7.5\% SDS-PAGE and transferred to PVDF membranes. After transfer, membranes were incubated with primary anti-phospho-ERK1/2 (1:1000), followed by incubation with a secondary biotinylated 

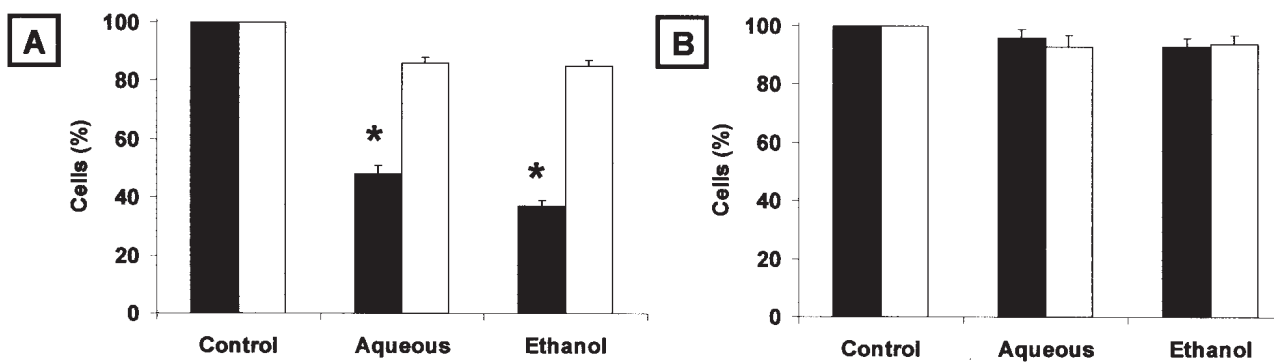

Figure 3. Effect of aqueous and ethanol extracts from A. californica (A) and L. porteri (B) on the growth of MCF-7/AZ (closed bars) and HCT8/E11 (open bars) cells. Cells were treated with $50 \mathrm{mg} / \mathrm{ml}$ of extracts for 4 days, and the number of cells was determined by counting and is expressed as a percentage of control cells. Bars and flags indicate mean values and standard deviations. *Indicates statistical difference from the control.

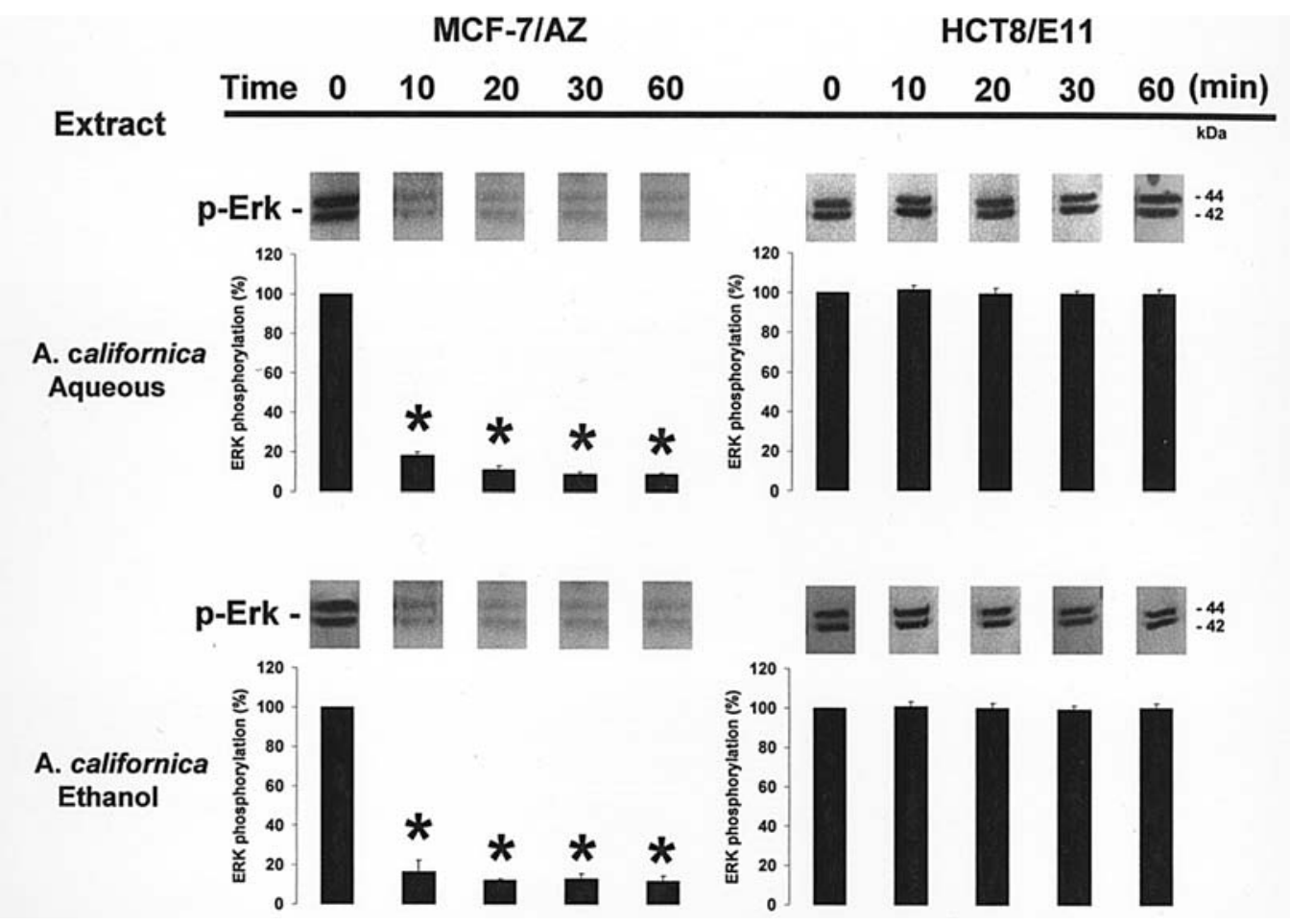

Figure 4. Time-dependent effect of aqueous and ethanol extracts from A. californica on ERK1/2 phosphorylation. MCF-7/AZ and HCT8/E11 cells were exposed to $50 \mathrm{mg} / \mathrm{ml}$ of extracts. Western blot analysis and immunostaining were done with anti-phospho ERK1/2, and the results are presented as the percentage of unexposed cells. Bars and flags indicate mean values and standard deviations. * Indicates statistical difference from the control.

antibody (1:1000) and developed by an ECL detection kit (Vector Labs, Burlingame, CA, USA). Membranes were imaged and analyzed on the BioChemi System and analysis software (UVP, Upland, CA, USA).

Statistics. All treatments were matched and carried out at least three times. The Student's t-test $(95 \%)$ was used for statistical evaluation of the sulforhodamine B assay, cell counting and ERK1/2 phosphorylation assay. Levels of phospho-ERK1/2 were quantified using Scion Image statistical software (Scion Corporation, MD, USA).

\section{Results}

Effect of plant extracts on cell viability. The results of the cytotoxic effect of extracts from A. californica and L. porteri on $\mathrm{MCF}-7 / \mathrm{AZ}$ and $\mathrm{HCT} 8 / \mathrm{E} 11$ after $24 \mathrm{~h}$ exposure, as determined by the MTT assay, are shown in Fig. 1. A concentration-dependent decrease in cell viability was observed for both extracts from A. californica on MCF-7/AZ and HCT8/E11 cancer cells. No significant change in cell viability was detected for extracts from $L$. porteri in either cell line (data not shown). For further experiments, we chose a concentration of $50 \mu \mathrm{g} / \mathrm{ml}$, leaving approximately $80 \%$ of the cells viable.

\section{Effect of plant extracts on cell growth}

Sulforhodamine B assay. Aqueous and ethanol extracts of A. californica markedly inhibited growth of MCF-7/AZ cells in the assay in a concentration-dependent manner (Fig. 2). Growth of HCT8/E11 cells was not significantly altered (data not shown). Both extracts from L. porteri showed no effect on the growth of MCF-7/AZ and HCT8/E11 cells (data not shown).

Cell counting. Consistent with the results obtained from the sulforhodamine B assay (Fig. 2), exposure of MCF-7/AZ cells to $50 \mu \mathrm{g} / \mathrm{ml}$ (80\% viability) of both extracts from A. californica showed a $50 \%$ decrease in cell proliferation 
compared to the controls. These extracts had no antiproliferative effect on HCT8/E11 cells (Fig. 3A). As shown in Fig. 3B, the extracts of L. porteri did not exhibit inhibitory effects on cell proliferation.

Time-dependent effect of extracts on phosphorylation of ERK1/2. MCF-7/AZ cells exposed to $50 \mu \mathrm{g} / \mathrm{ml}$ of aqueous and ethanol extracts of $A$. californica decreased ERK activities in a time-dependent manner compared to controls. No change in the phosphorylation level of ERK was observed in HCT8/E11 cells (Fig. 4). In addition, extracts of $L$. porteri did not alter ERK activity (data not shown). Total levels of ERK were unaltered upon exposure (data not shown).

\section{Discussion}

Medicinal plants are excellent sources of new drug candidates. Forming a basis for the treatment of diseases in both traditional and modern medicine, they continue to play a crucial role in the primary health care of many cultures (14). The World Health Organization supports interaction with traditional medicine with the view of providing scientific evidence for effective remedies (15). Many allegations have been made regarding the beneficial effects of plants in cancer treatment (16). These numerous allegations, however, may be viewed with some skepticism as cancer is poorly characterized in terms of folklore and traditional medicine. The discovery and development of potent anticancer agents such as vinblastine and vincristine, isolated from the Madagascar periwinkle, Catharanthus roseus, provided convincing evidence that plants could be a source of novel effective cancer chemotherapeutic agents (17). While the natural product isolated as the bioactive compound might not be appropriate for development as an effective drug, it can serve as a suitable lead compound for conversion into a clinically useful agent with improved physicochemical and pharmacological properties. Topotecan and irinotecan are two synthetic analogues derived from camptothecin, designed to facilitate the parenteral administration of the compound by introducing functional groups to enhance solubility (18).

Native American tribes in New Mexico use medicinal plants to treat a broad range of diseases, including cancer, based on inherited ancestral experience. Scientific knowledge regarding biological activity and active components in L. porteri and A. californica is poorly defined (7). In the present study, we investigated the potential anticancer activities of aqueous and ethanol extracts from two Native American plants L. porteri and A. californica on the growth of human MCF-7/AZ breast and HCT8/E11 colon carcinoma cells. The aqueous and ethanol extracts from both medicinal plants showed no significant cytotoxicity effects at a concentration of $50 \mu \mathrm{g} / \mathrm{ml}$ as shown in the MTT studies. MCF-7/AZ cells exposed to aqueous and ethanol extracts from A. californica potently inhibited cell proliferation of MCF-7/AZ compared to unexposed cells, as determined by SRB studies and cell counting assays. The growth of HCT8/E11 was unaltered. Both extracts from L. porteri showed no activity on either cell line. To further explore intracellullar targets of A. californica extracts, we chose to study the activity level of ERK1/2.
The ERK signal transduction pathway regulates important cellular processes, including cell growth, differentiation and survival (8). The ERK1/2 tyrosine/threonine kinases are activated by a wide variety of mitogenic stimuli that interact with distinct cell surface receptors resulting in the activation of downstream signaling molecules (19). We speculated that changes in ERK activity could be responsible for the growth inhibitory effects, given that many plant-derived components modulate ERK activities to elicit their antineoplastic actions (20). Hence, MCF-7/AZ cells exposed to $50 \mu \mathrm{g} / \mathrm{ml}$ of both extracts of A. californica significantly decreased ERK activities in a time-dependent manner compared to the controls. No change in the phosphorylation level of ERK was observed in HCT8/E11 cells. Furthermore, extracts of $L$. porteri did not alter ERK activity.

These results suggest that $L$. porteri does not exert anticancer activity, while $A$. californica inhibits the growth of human breast cancer cells in an ERK-dependent way. This further indicates that components comprised of A. californica extracts may have promise for use as an agent to prevent or delay the onset of cancer.

\section{Acknowledgements}

This work is supported by the U.S. National Institutes of Health (RR-16480) under the BRIN/INBRE program of the National Center for Research Resources and the New Mexico Tech startup funds. Amber Daniels was supported by the Lawrence B. Matthews scholarship.

\section{References}

1. American Cancer Society: Surveillance Research, 2004. In: Cancer Facts and Figures. American Cancer Society, Atlanta, GA, 2004.

2. Jessup JM, McGinnis LS and Winchester DP: Clinical highlights from the National Cancer Database 1996. CA Cancer J Clin 46: 185-187, 1996.

3. Abdulaev FI: Plant-derived agents against cancer. In: Pharmacology and Therapeutics in the New Millenium. Gupta SK (ed). Narosa Publishing House, New Delhi, pp345-354, 1993.

4. Johnson IS, Armstrong JG and Gorman M: The Vinca alkaloids: a new class of oncolytic agents. Cancer Res 23: 1390-1397, 1963.

5. Wani MC, Taylor HL and Wall ME: Plant antitumor agents. The isolation and structure of taxol, a novel antileukemic and antitumor agent of Taxus brevifolia. J Am Chem Soc 93: 2325-2327, 1971 .

6. Wall ME, Wani MC and Cook CE: Plant antitumor agents. The isolation and structure of camptothecin, a novel alkaloidal leukemia and tumor inhibitor from Camptotheca acuminata. J Am Chem Soc 88: 3888-3890, 1966.

7. Medina L, Lucero M, Holguin O, Estell R, Posakony J, Simon J and $\mathrm{O}^{\prime}$ Connel $\mathrm{M}$ : Composition and antimicrobial activity of Anemopsis californica leaf oil. J Agric Food Chem 53: 8694-8698, 2005.

8. Seger R and Krebs E: The MAPK signaling cascade. FASEB J 9: 726-735, 1995.

9. Yu R, Hebbar V, Kim DW, Mandlekar S, Pezzuto JM and Kong AN: Resveratrol inhibits phorbol ester and UV-induced activator protein activation by interfering with mitogen-activated protein kinase pathway. Mol Pharmacol 60: 217-224, 2001.

10. Bracke ME, Van Larebeke NA, Vyncke BM and Mareel MM: Retinoic acid modulates both invasion and plasma membrane ruffling of MCF7 human mammary carcinoma cells in vitro. $\mathrm{Br}$ J Cancer 63: 867-872, 1991.

11. Vermeulen SJ, Bruyneel EA, Bracke ME, De Bruyne GK, Vennekens KM, Vleminckx KL, Berx GJ, Van Roy FM and Mareel MM: Transition from the noninvasive to the invasive phenotype and loss of 3 -catenin in human colon cancer cells. Cancer Res 55: 4722-4728, 1995. 
12. Romijn JC, Verkoelen CF and Schroeder FH: Application of the MTT assay to human prostate cancer cell lines in vitro: establishment of test conditions and assessment of hormone-stimulated growth and drug-induced cytostatic and cytotoxic effects. Prostate 12: 99-110, 1988.

13. Skehan P, Stroeng R, Scudiero D, Monks A, McMahon J, Vistica D, Warren JT, Bokesch H, Kenney S and Boyd MR: New colorimetric cytotoxicity assay for anticancer drug screening. J Natl Cancer Inst 82: 1107-1112, 1990.

14. Farnsworth NR, Akerele O, Bingel AS, Soejarto DD and Guo Z: Medicinal plants in therapy. Bull World Health Organ 63: 965-981, 1985.

15. World Health Organization, Traditional Medicine. Fact Sheets, 2003.
16. Hartwell JL: Plants used against cancer. A survey. Quaterman Publications, Lawrence, MA, 1982.

17. Noble RL: The discovery of the vinca alkaloids-chemotherapeutic agents against cancer. Biochem Cell Biol 68: 1344-1351, 1990.

18. Garcia-Carbonero R and Supko JG: Current perspectives on the clinical experience, pharmacology, and continued development of the camptothecins. Clin Cancer Res 8: 641-661, 2002.

19. Pearson G, Robinson F, Gibson T, Xu B, Kandikar M, Berman K and Cobb MH: Mitogen-activated protein (MAP) kinase pathways: regulation and physiological functions. Endocr Rev 22: 153-183, 2001.

20. Hollosy F and Keri G: Plant-derived protein tyrosine kinase inhibitors as anticancer agents: current medicinal chemistry. Anti-Cancer Agents 4: 173-197, 2004. 